\title{
ARTE E CULTURA EM TEMPOS DE DISPUTAS DE NARRATIVAS
}

\author{
Guilherme Marcondes dos Santos* \\ Marcelo Ribeiro Vasconcelos ${ }^{* *}$
}

O advento de uma autodenominada nova direita no campo político brasileiro, não trouxe apenas a oposição aos programas político-sociais que vinham sendo implementados nas últimas décadas. $\mathrm{O}$ ano de 2018 pode ser, assim, encarado como um marco importante para o debate acerca de disputas de narrativas entre grupos políticos que buscam escrever, ou reescrever, o passado e encaminhar o Brasil em distintos rumos. Neste cenário, o campo artístico e cultural não passou ileso. Questionamentos sobre programas de financiamento da área cultural, com consequente cancelamento, e mesmo a censura a exposições se tornaram comuns. Atentando às disputas que têm ocorrido nos campos da arte e da cultura, este dossiê reúne, portanto, pesquisadores/as/us que abordam aspectos desta chamada "disputa de narrativas".

Palavras-chave: Arte; Cultura; Política; Disputa de Narrativas.

\section{APRESENTAÇÃO}

O campo das artes visuais, em suas diferentes dimensões, esteve envolvido nos últimos anos em acirradas disputas simbólicas e políticas. Mesmo que, historicamente, a arte tenha servido de espaço para críticas e comentários sobre a sociedade de seu tempo, tal fenômeno parece assumir, atualmente, novas formas. Tem sido possível observar uma dimensão política das artes cujo novo sentido procura colocar no centro do debate pautas sociais de grupos minoritários - mulheres, indígenas, LGBTQIA+'s, negros etc. Contudo, ao mesmo tempo em que tais debates adentram salas expositivas, praças públicas, universidades e toda sorte de lugares em que artistas apresentam seus trabalhos, também foi possível observar o advento de uma autodenominada nova direita no campo político brasileiro que se opôs, por diversas vezes, a tais manifestações artísticas. Questionamentos sobre programas de financiamento da área cultural, cancelamento e censura de exposições e outras acusações tornaram-se recorrentes nas "disputas de narrativas" que se desenrolaram nos últimos anos.

\footnotetext{
*Universidade Estadual do Ceará (PPGS/UECE), Av. Dr. Silas Munguba, 1700 - Itaperi, Fortaleza - CE, CEP 60741-000, Brasil. guilherme.marcondes@uece.br

(iD http://orcid.org/0000-0001-6114-7944

** Universidade Federal de Juiz de Fora, Instituto de Artes e Design / Programa de Pós-Graduação em Artes, Cultura e Linguagens (PPGACL) - Campus Universitário. Rua José Lourenço Kelmer, s/n Bairro São Pedro - Juiz de Fora - MG - CEP 36036-900 Brasil. marcelo.ribeiro84@gmail.com

(D) http://orcid.org/0000-0001-7817-9694
} 
Neste contexto, a mostra Queermuseu: Cartografias da Diferença na Arte Brasileira, de curadoria de Gaudêncio Fidélis, foi, possivelmente, o maior exemplo do tipo de conflito desenrolado entre artistas, público e instituições. Em setembro de 2017, a exposição ocorrida em Porto Alegre acabou por ser encerrada às pressas em razão da pressão de grupos político-religiosos que acusavam a mostra de fazer apologia à pedofilia, zoofilia e blasfêmia. Outro caso emblemático de tais conflitos ocorreu, no mesmo ano, em torno da performance La Bête, de Wagner Schwartz, que, em referência aos Bichos produzidos pela artista Lygia Clark, se apresentava nu em uma performance em que seu corpo poderia ser manipulado pelo público presente. Depois de uma apresentação na cidade de São Paulo, o artista foi acusado por incitar à pedofilia em razão da participação de uma criança do público em tal performance.

No intuito de estabelecer reflexões sobre este novo lugar da arte contemporânea e reunir jovens pesquisadores/as/us debruçados/as/us sobre tais problemas sociológicos, foi realizado em outubro de 2019 o Simpósio de Pós-graduandos intitulado Entrelaçamentos entre Arte e Politica: Debates Contemporâneos. O evento, que integrou o $43^{\circ}$ Congresso da Associação Nacional de Programas de Pós-Graduação e Pesquisa em Ciências Sociais (ANPOCS), foi idealizado como tentativa de compreender essas novas dinâmicas que estabelecem a arte como espaço de denúncia e superação de desigualdades históricas e também como um lugar de demandas e reconhecimentos de grupos minoritários. Para isso, é fundamental compreender não apenas a história das formas de entrelaçamento entre arte e política e os modos como agentes e instituições mobilizam e ressignificam tais tradições, mas também as formas como tais temáticas se inserem e/ou alargam as lógicas inerentes à arte contemporânea. O presente dossiê é composto por oito trabalhos produzidos por doze pesquisadores/as/us vinculados/as/us a departamentos e programas de pós-graduação de sete universidades brasileiras.

O artigo "O tropicalismo e seu projeto político ideológico: um exercício de leitura", de Rafael Marino, abre o dossiê retomando uma parte significativa da produção crítica acerca do movimento tropicalista para delinear o que pode ser visto como um projeto político e ideológico constituído a partir das obras dos artistas nele envolvidos. Ao fazer esse exercício, Marino retoma um momento significativo da história dos entrelaçamentos entre criação artística, identidade e transformação social no Brasil. Além disso, as abordagens sobre as identidades, a composição étnico-social e a realidade vivenciada pelos brasileiros presentes nas manifestações artísticas vinculadas ao tropicalismo permitiriam 
entender o movimento para além dos limites do campo da arte, estabelecendo-as como pertencente a um dos ramos do chamado "pensamento social brasileiro".

Em seguida, Tálisson Melo de Souza aborda a questão dos agentes e instituições mediadoras nos mundos da arte a partir da atuação de Walter Zanini como diretor do Museu de Arte Contemporânea da Universidade de São Paulo (MAC-USP) entre 1963 e 1978 e como curador da Bienal de São Paulo em suas 16a (1981) e $17^{a}$ (1983) edições. O artigo "Walter Zanini e as mediações da arte contemporânea no Brasil em redemocratização" chama a atenção para momentos-chave nos processos de emergência e consolidação da arte contemporânea no Brasil e para a importância do "ativismo institucional" exercido por Walter Zanini através do MAC-USP e da Bienal de São Paulo. Além do pioneirismo no exercício da atividade curatorial no Brasil, chama a atenção à participação de Zanini em prol do uso de tecnologias nas artes e de linguagens artísticas que se utilizam tais meios, como a videoarte.

O terceiro trabalho do presente dossiê, "Cordel-Jornal' e o ativismo negro: os cordéis da poetisa Jarid Arraes", já aborda muitos dos elementos que caracterizam a produção artística contemporânea. Diego Ramon Souza Pereira mobiliza a obra de Jarid Arraes para abordar questões referentes à produção contemporânea em artes e sua articulação com práticas tradicionais e ativismo político. No artigo, fica evidente que a atuação de Jarid Arraes enquanto poeta, blogueira e editora se unem a partir de sua militância e no seu esforço de construção de uma memória compartilhada sobre as "Heroínas Negras", mas que não se basta apenas no "resgate" desta, pois também foi responsável por estabelecer espaços virtuais de sociabilidades.

O último trabalho desta primeira seção do dossiê trata das disputas em torno da exposição Queermuseu, caso emblemático no que tange às narrativas e disputas simbólicas em torno das obras de arte lá expostas e os repertórios morais mobilizados no jogo de acusações/defesa da exposição. Outro ponto fundamental mobilizado por Sara R. de Andrade, em "A ascensão do Moralismo político e a reação dos públicos de arte", é a análise sobre o processo de midiatização de tais contendas através das redes sociais e a instrumentalização das narrativas em torno do evento por grupos distintos da chamada "nova direita", reforçando um sentimento de polarização política.

Os três artigos que constituem a segunda parte do dossiê foram escolhidos em razão da abordagem pertinente às temáticas tratadas na primeira seção. Mesmo sem possuírem questões diretamente vinculadas ao chamado "mundo da arte" e suas instituições constitutivas e tradições, todos os artigos a seguir estabelecem importantes 
reflexões acerca da intersecção entre as lutas simbólicas de grupos e movimentos políticos e identitários e um processo de politização do cotidiano. No artigo que abre a seção, "Pajubá: manifestação do ethos na polarização discursiva", Kaian Lago, Luis Henrique Boaventura e Ernani Cesar de Freitas retomam o problema das disputas simbólicas dadas nas redes sociais a partir de questões referentes às minorias LGBTQIA+ ao estabelecer uma análise dos discursos oriundos de grupos conservadores a partir de uma questão do ENEM 2018.

A questão da construção de narrativas e construção de sentidos políticos para as práticas cotidianas é também o cerne do debate estabelecido em "Cidade e política: disputas de narrativas no carnaval de rua carioca". As autoras Marina Bay Frydberg, Ana Clara Vega Martinez Veras Ferrera e Emily Cardoso Dias analisam, sobretudo, como os diferentes blocos e grupos organizados em torno das festas carnavalescas do Rio de Janeiro mobilizam uma série de argumentos e estéticas com o intuito de construir uma identidade que estabelece tais grupos enquanto um movimento de reinvindicação de direito à cidade.

Por fim, Natã Neves do Nascimento aborda o fenômeno dos slams em "“A Favela está passando a mensagem'- Construções de novas narrativas no Complexo do Alemão". Tais performances envolvem poesia oral, a interação - e intervenção - de um público, e abordam temáticas como homofobia, racismo, machismo e outras formas de opressões e desigualdade a partir de um ponto de vista de grupos subalternos.

Concluindo o dossiê após as duas seções de artigos, temos o relato de pesquisa "Etnografia de uma exposição do Museu da Arte Contemporânea do Ceará", de Maíra Rufino. O relato aborda uma série de temas pertinentes para futuras pesquisas na área da sociologia e antropologia da arte e da cultura ao descrever e analisar a exposição Zona de Remanso, realizada no Museu de Arte Contemporânea do Ceará (MAC-CE). A pesquisadora ressalta as formas como os trabalhos presentes na exposição apresentam narrativas sobre a trajetória dos/das/dus artistas negros/as/es e sua difícil inserção no sistema institucional que constitui a arte contemporânea, além de elementos sobre a condição específica de tais questões no estado do Ceará.

Com estes trabalhos, os organizadores e o comitê editorial da revista Encantar esperam contribuir para a consolidação da sociologia da arte no Brasil. No contexto brasileiro, a consolidação de tal campo de pesquisas significa o estabelecimento de um paradigma em que a arte é tomada como uma esfera social regida por regras que delimitam o espaço de ação dos indivíduos, grupos e instituições e acabam por construir cotidianamente aquilo que é reconhecido como arte. $\mathrm{Na}$ medida em que a arte contemporânea é entendida sob tal ponto de vista, é preciso atentar, especialmente, para 
uma crescente presença de uma dimensão política nas lutas por legitimação e reconhecimento que constituem a arte contemporânea, que tem mobilizado cada vez mais questões como o preconceito e as opressões de gênero, o racismo em seus diferentes matizes, etnicidades, as temáticas do trabalho, das classes sociais e do consumo. Arte, neste sentido, é conhecimento e como tal compõe a esfera do poder, sendo assim, é também um campo privilegiado para análise e reflexão acerca dos fatos da vida social.

Recebido para publicação em 18/05/2021

Aceito em 01/06/2021

Guilherme Marcondes dos Santos - Pós-doutorando no Programa de Pós-Graduação em Sociologia da Universidade Estadual do Ceará (PPGS/UECE). Doutor e mestre pelo Programa de Pós-Graduação em Sociologia e Antropologia da Universidade Federal do Rio de Janeiro (PPGSA/UFRJ). Graduado em Ciências Sociais (bacharelado e licenciatura) pela Universidade Federal do Rio de Janeiro (UFRJ). Foi Coordenador de Pesquisa e Memória do Museu Bispo do Rosário Arte Contemporânea (mBrac) e assistente de pesquisa no projeto Difusão e Educação Patrimonial do Acervo Histórico do CPDOC/FGV. Atualmente, é pesquisador associado ao Núcleo de Sociologia da Cultura da Universidade Federal do Rio de Janeiro (NUSC/UFRJ) e do GRUA - Grupo de Reconhecimento de Universos Artísticos/Audiovisuais: http://www.grua.art.br (CNPq).

Marcelo Ribeiro Vasconcelos - Professor Colaborador no Programa de Pós-Graduação em Artes, Cultura e Linguagens da Universidade Federal de Juiz de Fora (PPGACL/UFJF). Doutor em Sociologia (IFCH/UNICAMP). Mestre em Sociologia (PPGSA/UFRJ). Pesquisador associado ao Núcleo de Sociologia da Cultura da Universidade Federal do Rio de Janeiro (NUSC/UFRJ). Coordenador da Plataforma Mario Pedrosa Atual. 